\title{
ANALYSIS OF EXPANSION MESENCHYMAL STROMAL CELLS IN PATIENTS WITH LOW RISK MYELODYSPLASTIC SYNDROME
}

\author{
Fernando Barroso Duarte 1 , Romélia Pinheiro Gonçalves Lemes ${ }^{3}$, João Paulo Vasconcelos ${ }^{1}$, Francisco \\ Dário Rocha ${ }^{1}$, Ilana Zalcberg ${ }^{1}$, Diego Coutinho ${ }^{1}$, Lúcia Silla², Vanessa Valim², Maritza Cavalcante \\ Barbosa ${ }^{3}$, Talyta Ellen de Jesus dos Santos ${ }^{3}$, Luciana Barros Carlos ${ }^{4}$, Paulo Leitão de Vasconcelos . \\ ${ }^{1}$ Department of Surgery, Federal University of Ceará - Brazil ${ }^{2}$ Cellular Therapy Center of Hospital de Clinicas de Porto Alegre, \\ Center for Experimental Research, Porto Alegre - Rio Grande do Sul - Brazil. ${ }^{3}$ Research Laboratory in Hemoglobinopathies \\ and Genetics of Hematologic Diseases, Federal University of Ceará-Brazil ${ }^{4}$ Laboratorio de Criobiologia do Hemoce
}

Correspondence to: Fernando Barroso Duarte - nutriquimio@uol.com.br

\begin{abstract}
Myelodysplastic syndromes (MDS) comprise a heterogeneous group of clonal hematopoietic disorders characterized by ineffective hematopoiesis, cytopenias and dysplasia and one or more lineages. The stratification of MDS is made based on the percentage of bone marrow blasts, number of cytopenias and karyotype at diagnosis. Somatic mutations in the p53 tumor suppressor gene are found in approximately $50 \%$ of all human tumors, making it the most commonly mutated gene. The expression of p53 protein and the study of mutations is especially needed in the prognosis of MDS. In this context, the study aims to evaluate the expansion of mesenchymal stromal cells (MSCs) and the expression of p53 protein in patients with SMD, low risk, according to the International Prognostic System (IPSS), in order to demonstrate the importance of these evaluations also diagnostics. This is a cross-sectional analytical study with review 3 adult patients of both sexes, the diagnosis of low-risk MDS receiving outpatient treatment at the University Hospital Walter Cantídio (HUWC). MSCs were characterized by immunophenotyping and screening of mutation of the p53 gene by Real Time PCR System (Applied Biosystems). For data analysis, the statistical software was used GraphPadPrism 5.0. Statistical differences between groups were checked by Student t or Mann-Whitney's test significance level was $p<0.05$ for all analyzes. The results showed a smaller expansion of MSCs in the bone marrow of patients with MDS compared with a control group. A survey of mutation of the p53 gene was negative in all patients. The results demonstrate an impairment in the growth of MSCs in patients with MDS, collaborating with the hypothesis that medullary microenvironment in MDS may be compromised contributing greater understanding of disease mechanisms. However studies with larger sample should be conducted in order to establish the best results.
\end{abstract}

Key words: MDS; hematopoietic cells; mesenchymal cells; TP53 mutation.

\section{INTRODUCTION}

Mesenchymal stromal cells (MSCs) are a group of clonogenic, cells present in the bone marrow stroma, with potential to differentiate into various cell lineages. They propitiate the production and differentiation of hematopoietic stem cells in the bone microenvironment. In the bone marrow match $0.01 \%$ to $0.0001 \%[1,2]$. MSCs are multipotent expressing positivity for CD73, CD90 and CD105 markers, and lack of expression of CD14, CD34, CD45, CD19, HLADR, CD3, CD 1 1b, CD8, CD4, CD16 and CD 56 in 95\% of the cells in cultures. MSCs can be isolated from bone marrow by various methods, expandable pontencial maintaining their pluripotency and growth, with a doubling time which varies with the donor $[3,4]$.

Myelodysplastic syndromes (MDS) comprise a heterogeneous group of clonal hematopoietic disorders characterized by ineffective hematopoiesis, cytopenias and dysplasia and one or more lineages. The stratification of MDS is made based on the percentage of bone marrow blasts, number of cytopenias and karyotype at diagnosis. Somatic mutations in the p53 tumor suppressor gene are found in approximately $50 \%$ of all human tumors, making it the 
most commonly mutated gene. The expression of p53 protein and the study of mutations is especially needed in the prognosis of MDS [4].

Several in vitro studies show that the bone marrow of patients with MDS has a high rate of cell proliferation and cell death (apoptosis). The paradox in a hypercellular marrow peripheral cytopenias in MDS can be attributed to several mechanisms, such as changes in its own hematopoietic cells, changes in the expression of molecules involved in apoptosis (Fas, Bcl-2, caspase), abnormalities in the cell cycle as well as presence of changes in the stroma $[4,5]$ component.

The SMD has a high rate of ineffective hematopoiesis, manifested by anemia, neutropenia and / or thrombocytopenia. Besides the fact that the impairment also appears to occur in the bone marrow microenvironment, and MSCs. The ineffective hematopoiesis, is characterized by increased apoptosis, present in approximately $75 \%$ of patients with MDS $[6,7,8]$.

In this context, this study aims to evaluate the expansion of MSCs in cultures of patients with low-risk MDS and compare with those of healthy donors. Moreover, determining the expression of p53 gene in patients with MDS MSCs.

\section{CASUÍTICA AND METHODS}

\section{Casuistry}

This is a cross section of 3 adult patients, two females and one male, the diagnosis of low-risk MDS in a clinical service specializing in Fortaleza - Ceará. Risk stratification was performed by the International Prognostic Scoring System Revised (IPSS-R). Patient samples were obtained from bone marrow, during the period January to December 2013. Clinical data related to age, sex, blood count, bone marrow biopsy and bone were collected for analysis of medical records. The inclusion criteria in this study were samples at diagnosis, free of any type of treatment and availability of suitable cells for analysis.

All samples were obtained only after patients or guardians agree to participate and sign the "Statement of Consent", approved by the Federal University of Ceará Research Ethics Committee of the University Hospital Walter Cantídio (HUWC).

The control group $(n=4)$ of MSCs was obtained from the Cell Culture Laboratory and Molecular Analysis of Hematopoietic Cells, Center for Experimental Research / Hospital de Clinicas de Porto Alegre.

\section{Isolation, cultivation and expansion of MSCs}

The procedure for isolation, cultivation and expansion of MSCs was performed at the Laboratory of the Bank Umbilical Cord Blood Center of Ceará-Hemoce. The criteria adopted for the characterization of MSCs were those of the International Society for Cellular Therapy (ISCT) [9].

MSCs were isolated from bone marrow samples from patients with MDS (3 samples) and control subjects (6 samples) in culture medium poor in high concentrations of glucose and amino acids and proteins (fetal bovine serum). After counting the cells of the bone marrow aspirate about $1 \mathrm{x} \llbracket \rrbracket 10 \wedge 6$ cells $/ \mathrm{ml}$ were subjected to culture in bottles of $25 \mathrm{~cm} \wedge 2$ in a-MEM medium (Gibco-BRL, Gaithersburg, MD, USA) supplemented with antibiotics and with $15 \%$ fetal bovine serum (fetal bovine Serum Standard - $\wedge$ TM HyClone, Logan, UT, USA). Cells were cultured in a humidified $37^{\circ} \mathrm{C}$ incubator with 5\% CO 『》_2. After 3 to 5 days, it was able to remove nonadherent cells and new culture medium added. Every 2 or 3 days, the medium was changed and the cell culture was maintained until reaching a confluence of $70-90 \%$.

When they reach this confluence, MSCs were subjected to treatment with $1 \mathrm{ml}$ of trypsin-EDTA $1 \times(0.05 \%$ Tripsin

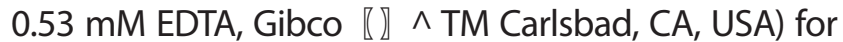
2-4 minutes at $37^{\circ} \mathrm{C}$. After inactivation of trypsin, cell suspension was washed, resuspended in culture medium and plated at a density of $5 \times 10 『 \rrbracket \wedge 4$ cells $/ \mathrm{cm}$ $\wedge 2$. Upon reaching the $3 \mathrm{rd}$ passage, the cells were subjected to the analyzes provided.

\section{immunophenotyping}

In flow cytometry, the cell suspension passes through a channel system which generates a laminar flow cell. A light beam hits these cells suffering deviation according to the physical characteristics of the same: cell size, granularity, internal complexity of the cell.

The monoclonal antibodies used is conjugated with three different fluorochromes: phycoerythrin (PE phycoeritrin the English), fluorescein isothiocyanate (FITC, fluorescein isothiocyanate English), PerCP (peridinin chlorophyll English). Positive and negative controls were included for proper calibration of the device, analyze the results and define the positivity of the sample.

The labeling of cells occurred after culturing MSCs reach the third pass, they were trypsinized, centrifuged, and the supernatant was discarded, leaving 
approximately $1.5 \mathrm{~mL}$ of media then held for cell counting. To perform labeling cells with monoclonal antibodies it takes a minimum of $5 x \llbracket \rrbracket 10 \wedge 5$ cells per tube, so after counting was performed in adjusting the final volume of cell suspension to that amount of cells were in a volume of $100 \mathrm{ul}$ in which were added $5 \mu \mathrm{l}$ of a fluorochrome-labeled antibody (FITC, PE or PerCP). After addition of the antibody sample was incubated in the dark for 15 minutes, then washed with $1 \times$ PBS, centrifuged and supernatant discarded, the cell pellet was added $100 \mathrm{ul}$ of $1 \mathrm{x}$ PBS. Once the cell suspension has been marked by the technique described, proceeded to the acquisition of fluorescence intensity in the cytometer.

Immunophenotyping of cells was performed using monoclonal antibodies which recognize antigens on the cell surface membrane. For the identification of these cells was assembled a panel containing the following markers CD105 PE (Serothec, Oxford, England), CD73 PE, CD45 FITC, CD14 PE, CD34 FITC, CD90 PE, CD13 PE (Becton Dickinson, San Jose, CA, USA ), CD140B PE, CD146 PE and CD31 FITC.

\section{The sequencing of the TP53 gene}

Mutational analysis of the TP53 gene was performed in the Laboratory of Molecular Biology of the Transplant Center Bone Marrow (CEMO) Cancer Institute (INCA) in Rio de Janeiro, by direct sequencing. Exons 3 - 9 gene were amplified by PCR from DNA extracted from MSCs. The PCR primers and conditions for amplification of genomic DNA followed established by the International Agency for Research on Cancer (p53. iarc.fr/ProtocolsAndTools.aspx). All PCR products were confirmed by $1.5 \%$ agarose gel, purified using the Wizard SV Gel kits and PCR Clean-Up (both Promega) and sequenced by an automatic sequencer 16 capillaries (ABI PRISM ${ }^{\circledR} 3100$ Genetic Analyzer, Applied
Biosystems). The sequence data files were analyzed using Mutation Surveyor (SoftGenetics) software. All variants were found compared with databases: Cosmic, dbSNP, and 1000 genomes UniProtKB

\section{Statistical Analysis}

Results were expressed as mean \pm standard error of the mean. For data analysis, the statistical software was used GraphPadPrism 5.0. Statistical differences between groups were checked by Student $t$ or Mann-Whitney tests. The level of significance was set at $p<0.05$ for all analyzes.

\section{RESULTS}

A total of three patients with low-risk MDS were analyzed for the expansion of mesenchymal cells and compared with a control group consisting of individuals considered healthy. Of the three patients studied one being female 74 years old, diagnosed with SMD hypocellular variant hypocellular marrow and $0.8 \%$ blasts; bone marrow biopsy with $20 \%$ diseritropoese and dismegacariocitopoese and Normal reticulin; Karyotype 46, XX; immunohistochemistry for p53 and negative for CD34 positive megakaryocytes; IPSS intermediate 1 with good clinical outcome. Patient with 58 year old female with pancytopenia; hypocellular marrow with $4 \%$ blasts; with hypercellular bone marrow biopsy, 50\% of diseritropoese and dismegacariopoese; karyotype 46XX. The male patient of 78 years; CRDM; IPSS intermediate 1 ; karyotype $46, \mathrm{XY}$, normocellular marrow with moderate and mild diseritropoese and disgranolopoese dismegacariopose and presence of $0.9 \%$ blasts; hypercellular bone marrow biopsy with diseritropoese, disgranulopoese and dismegacariopoese and reticulin grade 1 ; immunohistochemistry for $\mathrm{p} 53$ positive focal nuclear pattern.

TABLE 1 - Clinical characteristics of patients with myelodysplastic syndrome diagnosis $(n=3)$

\begin{tabular}{|c|c|c|c|}
\hline VARIABLES & PATIENT 1 & PATIENT 2 & PATIENT 3 \\
\hline Age (years) & 78 & 54 & 78 \\
\hline Gender & Female & Male & Female \\
\hline Cytogenetics, n (\%) & Karyotype Normal & Karyotype Normal & karyotype Normal \\
\hline IPSS & Intermediate 1 & Intermediate 1 & Intermediate 1 \\
\hline IPSS- R & Low & Low & Low \\
\hline \multicolumn{4}{|c|}{ hematological Prâmetros } \\
\hline $\mathrm{RBC} / 1012 / \mathrm{L}$ & 3.72 & 3.22 & 3.81 \\
\hline Hemoglobin, g/dL & 10.8 & 10.6 & 12.1 \\
\hline Hematocrit, \%. & 32.7 & 31.0 & 34.7 \\
\hline leukocytes /L & 3.700 & 2.924 & 3273 \\
\hline Platelet/L & 116.000 & 42090 & 49530 \\
\hline
\end{tabular}


In Figure 1 we can see confirmation of the origin of MSCs through the characteristic profile by immunophenotyping.

In relation to research the expansion of mesenchy- mal cells in patients compared to the control group we observed a significant decrease in the group of MDS patients compared to the control group. The analysis of mutations in the $\mathrm{p} 53$ gene was negative in patients with MDS MSCs.
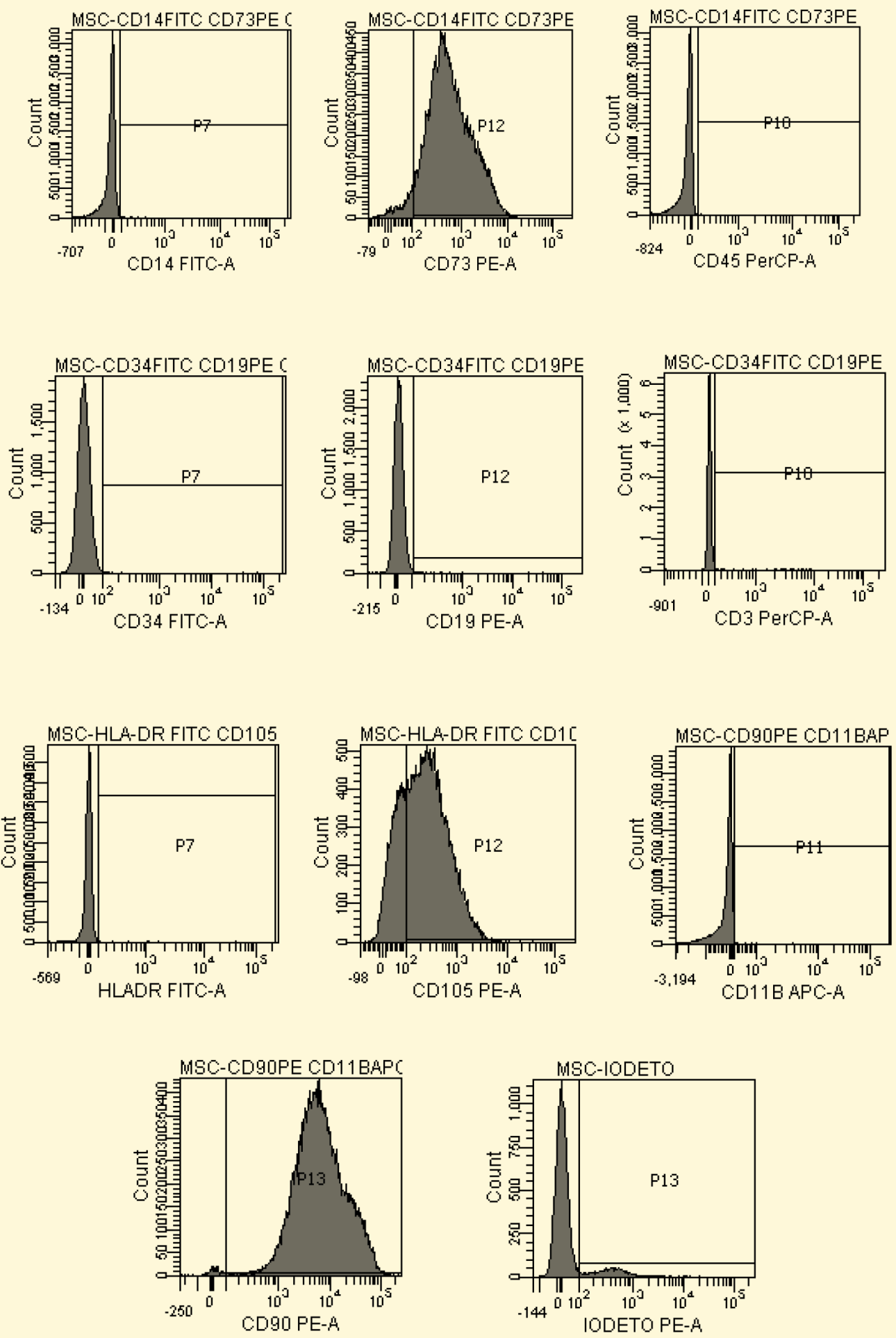

FIGURE 1 - Phenotypic analysis of MSCs in patients with low-risk MDS ( $n=3)$. Feasibility: $89.7 \%$ (10.3\% dead cells) 
TABLE 2 - Analysis of expansion of MSCs in patients with low-risk myelodysplastic syndrome and apparently healthy individuals

\begin{tabular}{c|c|c|c|c|c}
\multicolumn{2}{c|}{$\begin{array}{c}\text { MONONUCLEAR CELLS } \\
\text { RECOVERED FROM THE } \\
\text { BAG AND FILTER }\end{array}$} & p0 & p1 & p2 & p3 \\
\hline CONTROL & 15.700 .000 & 1.099 .000 & 48.081 .250 & 9.676 .351 .563 & 84.635 .821 .667 \\
\hline CONTROL & 150.000 .000 & 12.400 .000 & 640.666 .667 & 125.730 .833 .333 & 541.480 .788 .889 \\
\hline CONTROL & 28.000 .000 & 6.981 .333 & 1.087 .924 .444 & 381.226 .857 .407 & 2.328 .025 .342 .568 \\
\hline CONTROL & 194.000 .000 & 19.788 .000 & 1.261 .485 .000 & 147.698 .868 .750 & 746.371 .616 .750 \\
\hline CONTROL & 7.400 .000 & 740.000 & 46.250 .000 & 12.738 .020 .833 & \\
\hline CONTROL & 304.500 .000 & 23.548 .000 & 1.138 .153 .333 & 314.414 .858 .333 & \\
\hline PATIENT & 1.075 .000 & 2.200 .000 & 6.306 .667 & 40.867 .200 & 250.652 .160 \\
\hline PATIENT & 4.060 .000 & 4.300 .000 & 32.480 .000 & 329.130 .667 & 3.774 .031 .644 \\
\hline
\end{tabular}

TABLE 3 - Characterization of mutation of TP53 in MSCs in patients with low-risk MDS $(n=3)$

\begin{tabular}{|c|c|}
\hline PATIENT & MUTATION IN TP53 \\
\hline 1 & Absent \\
\hline 2 & Absent \\
\hline 3 & absent \\
\hline
\end{tabular}

\section{DISCUSSION}

In culture, MSCs are a population of cells with the morphological appearance of fibroblasts, adherent to plastic. The half-life is limited, with an average doubling time of 33 hours and a maximum overlap of about 40. Expands As the number lost their multipotential capacity and undergo apoptosis. The cell cycle studies in cultured human MSC show that while a small fraction of these cells proliferating (approximately $10 \%$ of cells are in $S+G 2+M$ phase) are most cells in the G0/G1 phase, comprising a minority of resting cells $[10,11]$.

Some aspects regarding the interactions between the neoplastic clone and the bone microenvironment has been rumored as one of the mechanisms of the pathophysiology of MDS. However, studies on the subject are scarce and therefore requiring research characterizing the bone marrow stromal cells in healthy individuals and in patients with malignant hematological diseases [12].

The development of MDS is a complex process, for which we propose a model with successive steps. In this model, an abnormal clone could interact with hematopoietic marrow microenvironment providing the altered neoplastic growth with normal shifting [13] hematopoiesis.

Studies evaluating the functionality and molecular phenotyping aspect of MSCs in patients with MDS have been documented. However the results are conflicting. In this study the degree of purity of MSCs was $89.7 \%$ of the cells present in the sample, we can affirm that the data obtained are in effect for these cells. We found that the pattern of growth of MSCs in patients with low-risk MDS was different from healthy subjects. There was a significant reduction in the MSCs expanssão of MDS patients compared to healthy bone marrow. The growth pattern of MSCs is controversial because some studies have described altered expansion $[11,14]$, while others have observed a similar growth of normal bone marrow [15] standard. The discrepancies may result attributed to the large variation in the growth of MSC in MDS subtypes or methodological used, among others. 
Regarding the immunohistochemical study of MSCs found that there was no difference in the pattern of patients with low-risk MDS, relative to healthy individuals. These results corroborate with the literature, which state that most studies agree that MSCs from MDS patients are identical to normal $[2,15]$ markers. Studies, but has shown that the expression of CD90, CD104 and lower CD105é MSCs in MDS patients

\section{CONFLICT OF INTEREST}

The authors declare no conflict of interest.

\section{REFERENCES}

1. Soenen-Cornu V, Tourino C, Bonnet ML et al. Mesenchymal cells generated from patients with myelodysplastic syndromes are devoid of chromosomal clonal markers and support short- and long-term hematopoiesis in vitro. Oncogene 2005;24:2441-2448.

2. Blau O, Hofmann WK, Baldus CD et al. Chromosomal aberrations in bone marrow mesenchymal stroma cells from patients with myelodysplastic syndrome and acute myeloblastic leukemia. Exp. Hematol. 2007;35:221-229.

3. Flores-Figueroa E, Arana-Trejo RM, Gutierrez-Espindola G, Perez-Cabrera A, Mayani H. Mesenchymal stem cells in myelodysplastic syndromes: phenotypic and cytogenetic characterization. Leuk.Res. 2005;29:215-224.

4. Santamaría C, Muntión S, Rosón B, Blanco B, López-Villar O, Carrancio $S$, et al. Impaired expression of DICER, DROSHA, SBDS and some microRNAs in mesenchymal stromal cells from myelodysplastic syndrome patients. Haematologica. 2012 Aug;97(8):1218-24

5. Shih AH, Levine RL. Molecular Biology of Myelodysplastic Syndromes. Seminars in Oncology. 2011; 38 (5): 613-20Stephenson J, Mufti GJ, Yoshida Y. Myelodysplastic syndromes: from morphology to molecular biology. Part II. The molecular genetics of myelodysplasia. Int J Hematol. 1993 Apr;57(2):99-112.
$[4,10,11]$. Finding attributed to alteration of the marrow stroma and hematopoietic cells.

Regarding the analysis of mutation of p53 gene mutation was not observed in MCSs in patients with MDS. Additional studies are needed to elucidate the mechanisms involved in the regulation of MCSs in MDS, so that we can establish the prognostic value of MCSs, the pathophysiology in this disease.

6. Malcovati L, Nimer SD. Myelodysplatia syndromes: diagnosis and staging. Cancer Control. 2008; 15(4):4-13.

7. Greenberg P, Cox C, LeBeau MM, Fenaux P, Morel P, Sanz G, et al: International scoring system for evaluating prognosis in Myelodysplastic syndromes. Blood. 89:2079-88, 1997.

8. Myelodysplastic Syndromes. NCCN Clinical Practice Guidelines in Oncology. v.2, Fort Washington, PA: NCCN, 2011.

9. Dominici M, Le BK, Mueller I et al. Minimal criteria for defining multipotent mesenchymal stromal cells. The International Society for Cellular Therapy position statement. Cytotherapy. 2006;8:315-317.

10. Campioni D, Moretti S, Ferrari L et al. Immunophenotypic heterogeneity of bone marrow-derived mesenchymal stromal cells from patients with hematologic disorders: correlation with bone marrow microenvironment. Haematologica 2006;91:364-368.

11. Flores-Figueroa E, Arana-Trejo RM, Gutierrez-Espindola G, Perez-Cabrera A, Mayani H. Mesenchymal stem cells in myelodysplastic syndromes: phenotypic and cytogenetic characterization. Leuk.Res. 2005;29:215-224.

12. Greenberg PL, Tuechler H, Schanz J, et al. Revised international prognostic scoring system for myelodysplastic syndromes. Blood. 2012;120: 2454-2465. 
13. Valent P, Horny HP, Bennett JM, et al. Definitions and standards in the diagnosis and treatment of the myelodysplastic syndromes: consensus statements and report from a working conference. Leuk Res 2007;31:727-36.

14. Tauro S, Hepburn MD, Bowen DT, Pippard MJ. Assessment of stromal function, and its potential contribution to deregulation of hematopoiesis in the myelodysplastic syndromes. Haematologica 2001;86:1038-1045.

15. Soenen-Cornu V, Tourino C, Bonnet ML et al. Mesenchymal cells generated from patients with myelodysplastic syndromes are devoid of chromosomal clonal markers and support short- and long-term hematopoiesis in vitro. Oncogene 2005;24:2441-2448. 